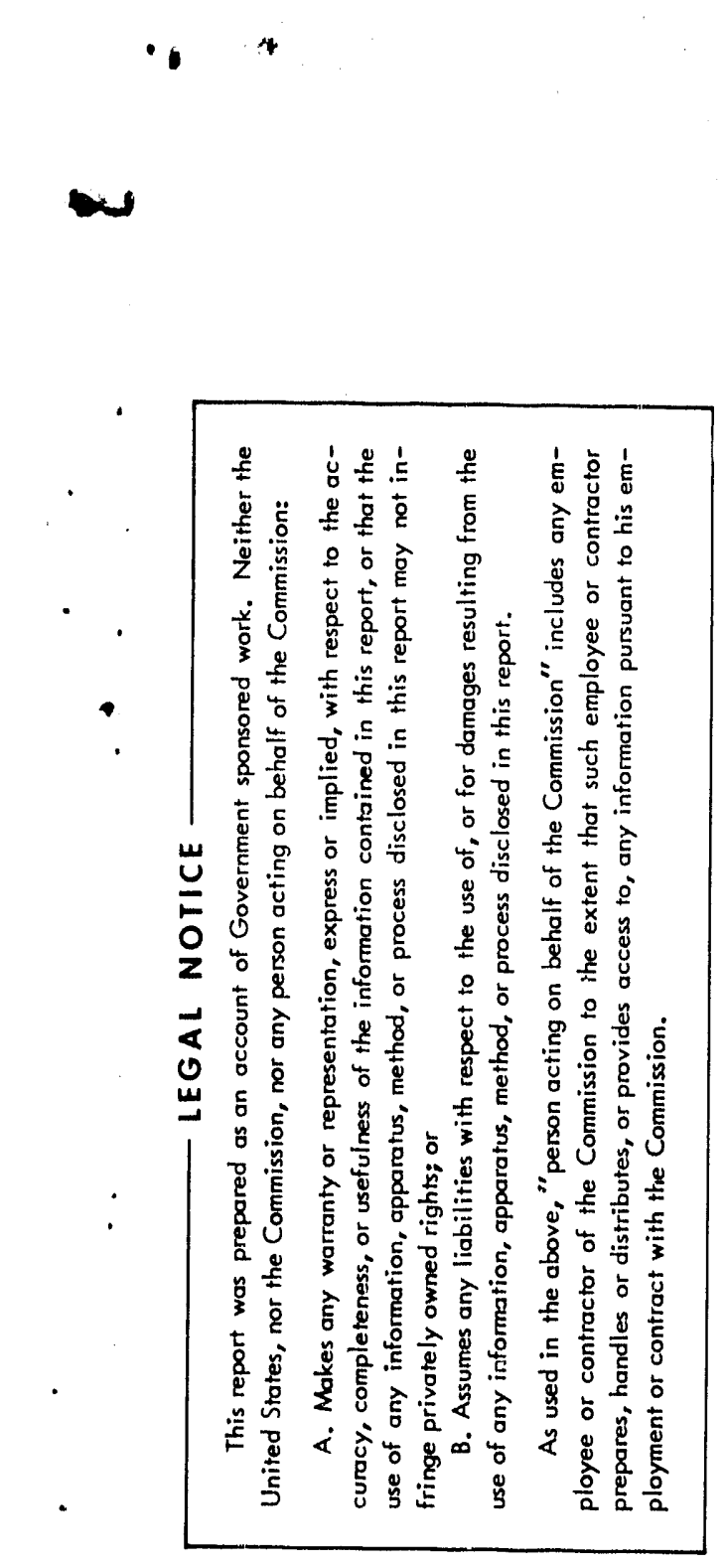

\title{
A STUDY OF CERTAIN PROPERTIES OF RUTHENIUM COMPOUNDS FOUND IN THE REDOX PROCESS
}

By

W. E. Gill

D. E. Wisehart

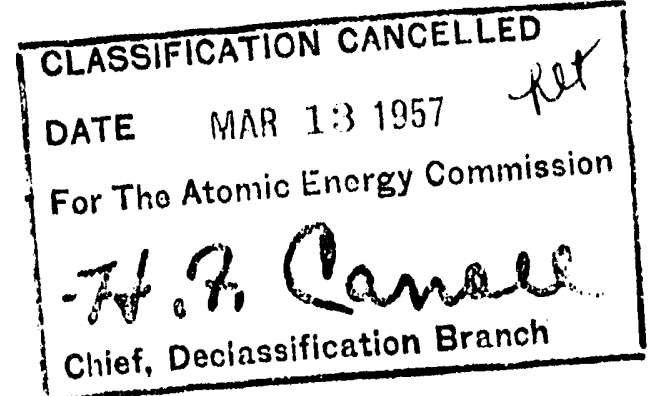

June 23, 1954

Hanford Atomic Products Operation Richland, Washington

UNITED STATES ATOMIC ENERGY COMMISSION Technical Information Extension, Oak Ridge, Tennessee
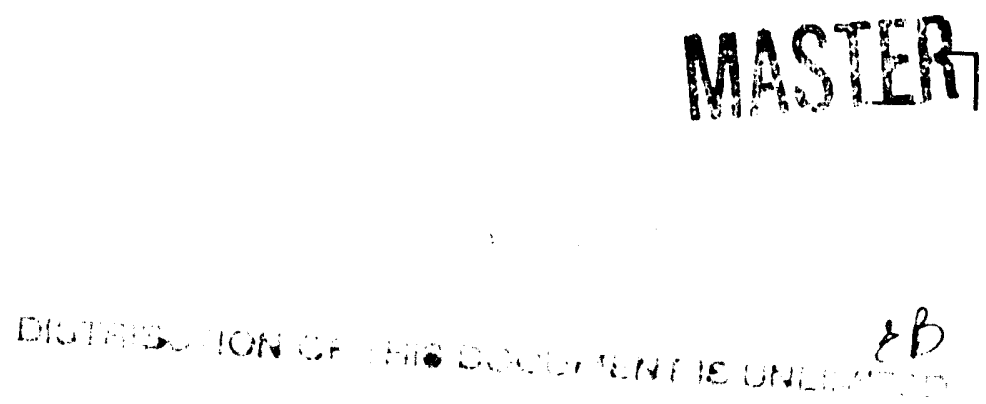
TO: FILE

\section{A STUDY OF CERTAIN PROPERTIES OF RUTHENIUM COMPOUNDS FOUND IN THE REDOX PROCESS}

During the current study by the Industrial Hygiene Unit of the penetration by zuthenium compounds of certain respirator filters and canisters used at the 202-S facility, some information was obtained which may be useful to others at HAPO.

In order to study the character of ruthenium compounds involved in the problem, laboratory study of non-radioactive ruthenium and field study of accessible parts of the process were mide.

A $500 \mathrm{ml}$ round-bottomed boiling flask was set up as an $\mathrm{RuO}_{4}$ generator to simulate oxidation. Ball and socket connections were used so that $U$ tubes, scrubbers, and other units could be readily placed in the sampling train. Commercial ruthenium chloride that had been fumed with $\mathrm{H}_{2} \mathrm{SO}_{4}$ and diluted, was

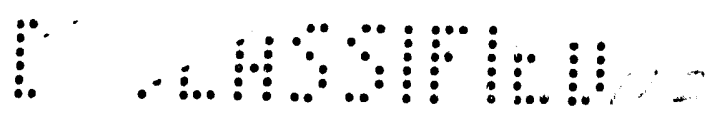




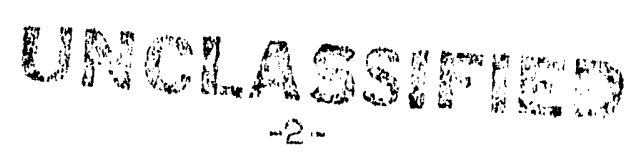

used as a source of rutbenilum. Potassjum periodate was used as the oxidizing agent. The RuO4 was removed from the flakk by draving an air stream through the generator solution in a manrer similar to sparging in the process.

As will be shown in äetail in a final extensive report, from $40 \%$ to $99 \%$ of the gaseous $\mathrm{RuO}_{4}$ passed through the vallous paper filter media tested. The use of activated charcoal and slica gel as adsorbing agents for gaseous RuO 4 was also investigated. Using the characteristic orange color produced qualitatively by $\mathrm{RuO}_{4}$ in $\mathrm{NaOH}$ solution as the indicator of penetration, $200 \mathrm{mg}$ of $\mathrm{RuO}_{4}$ was collected on one grar of charcoal before it ras sufficlently saturated to show penetration into the $\mathrm{NaOH}$ solution. However, within a few minutes the charcoal exploded with a flash of flame. For this reason, silica gel was tried. It was observed that at $25^{\circ} \mathrm{C}$, the $\mathrm{RuO}_{4}$ caused an immediate blackening of the silica gel at the upstream surface, and that this blackening progressed through the bed of silica gel as long as the passage of Rro/ continued. It seems probable that the black deposit was $\mathrm{RuO}_{2}$, resulting from the rapid decomposition of $\mathrm{RuO}_{4}$ as it was adsorbed on the silica gel.

It is likely that the $\mathrm{RuO}_{4}$ ad.orbed on the activated charcoal also decomposed. to $\mathrm{RuO}_{2}$ and oxygen in the same manner as that observed on the silica gel. The explosion could. well have been dixe to the secondary reaction of the oxygen with charcoul resulting in sportaneous combustion.

It was further observed that the black deposit on the silica gel was readily removed by leaching with hot HCl. One gram of the blackened silica gel was bolled for twenty minutes witib. six. sucessive $25 \mathrm{ml}$ portions of concentrated $\mathrm{HCl}$. This treatment removed all evidence of the black deposit on the allica gel, and the ruthenfum was recovered in the leach solution.

Gaseous $\mathrm{RuO}_{4}$ was passed through a 5 foot coll of $10 \mathrm{~mm}$ glass tubing for 30 minutes at $95^{\circ} \mathrm{C}$. No evidence of aecomposition of RuO 4 to form black $\mathrm{RuO}_{2}$ 
particles was observed.

Sillca gel was also used as a collecting agent for radioactive material in the ruthenium off-gas sample line. During the oxidation step at 202-S on May 28 between 1:32 and 1:47 P.M. an aerosol sample was collected below the JI filter by means of a sllica gel tube backed up by a sodium hydroxlde scrubber. The silica gel tube contained 1.7 microcuries of ruthenium (measured as total beta) and $6.3 \times 10^{-4}$ microcuries was found in the backup scrubber. For this single trial the silica gel tube had an efficlency of $99.96 \%$.

Possibly silica gel could be used effectively in respiratory equipment to filter out both gaseous $\mathrm{RuO}_{4}$ and the microscopic paxticles of ruthenium compounds that characterize the aerosol in the ruthenium off-gas lilne.

It is suggested that silica gel might be used to advantage in the process for the recovery of the radioactive gaseous ruthenfum tetroxide. Periodic leaching of the silica bed would dissolve the racioactive ruthenium and it could then be disposed of in the waste Iiquor.

The only readily accessible material from the ruthenium oxidation at the 202-S facjlity was in the ruthenium off-gas line. In order to study actual samples of ruthenium aerosols from the process, samples were collected below the Jl filter in the off-gas line.

Samples were collected by means of cascade Impactors, and with a sampling train consisting of parallel filter holders backed up on one side by a silica gel tube followed by a sodium hydroxide scrubber, and on the other by a sodiun hydroxide scrubber alone. Individual flow meters wexe placed in each parallel Iine, and the plant vacuum line was used.

Because of the sub-microscopic character of the ruthenium particles, electron micrographs were deemed necessary for adequate study. Representative electron photomicrographs are shown on pages 5 and 6 . 


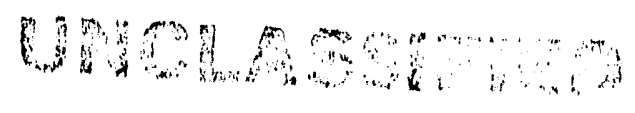

-it.-

HW -32175

The partilules shown in Figure 1 were prepared in the laboratory from nonradionctive ruthenium, and vary in size from less tikan 0.5 micron down to 0.01 micron. A deposit of film that is frobabiy composed of discrete particles below the limit of resolution of the electron microscope is also shown. A few aggregates and chains are larger. An interesting ring pattern is shown which indicates that much of the particulate matter may have been deposited as part of a microscopic aroplet. Photomferographs taken with the light microscope before the droplets were dry show a size and shape similar to the ring pattern of the electron photomicrographs.

Particles collected in the process off -gas line showed marked similarity to those produced in the laboratory. In Figure 2 are particles collected on the fourth stage of the cascade impartor from the ruthenium off-gas line at the 202-s Building. The material coliected on this stage comprised $99.4 \%$ of all radioactive material collected in the sample. Most of the particles were spheroids from 0.3 to 0.4 microns in diameter. Some chains and aggregates of these particles are shown. which are from 3 to 5 microns in length. Some smaller particles less than 0.1 micron are also present. Most of the particles shown here appear to have been depositied within microscopic aroplets similar to those shown in Figure 1. In Figure 3 the particles have been shadored to show their spheroid character, and the characterisic droplet pattern is obvious. Figure 4 shows a single arop pattern with particles and a dark deposit of film in the center. This was collected on atage 3 of the cascade impactor at the 202-5 Building。

The material shown in Figure 5 was collected by passing the air stream from the ruthenlum off-gas line over the electron microscope screens placed in the filter sampling unit. A few $0.3 \mu$ spheroids are shown, with a large number of particles less than 0.01 mj.cron in diameter.

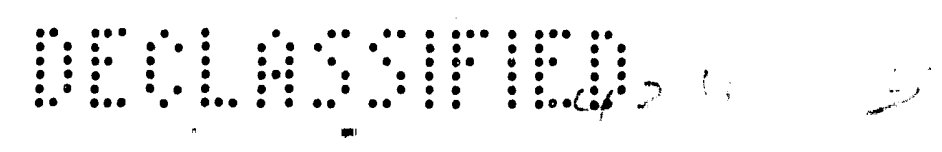




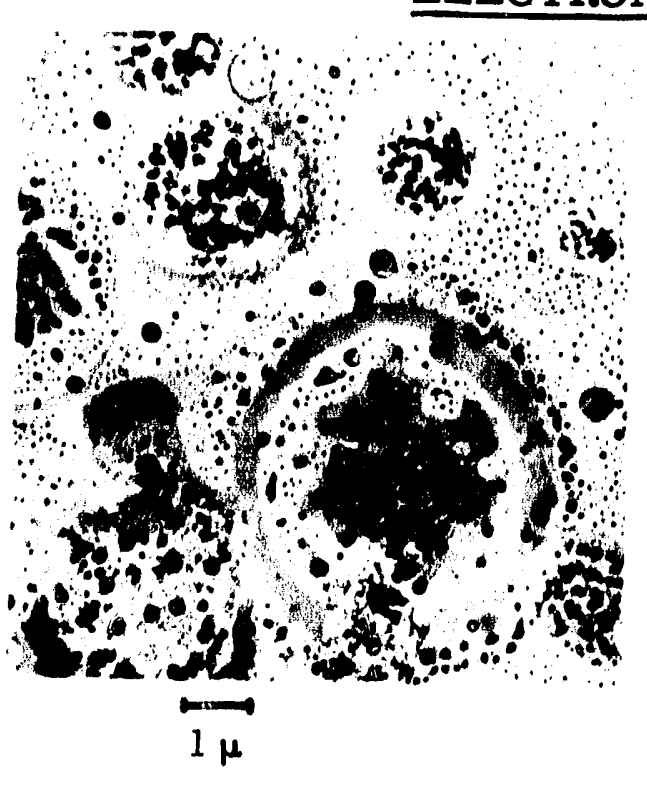

\section{FIGURE 2}

Particulate material collected on tine 4 th stage of a cascade impactor downstream from the $\mathrm{J} l$ filter in the ruthenium off gas line. $6000 \mathrm{x}$

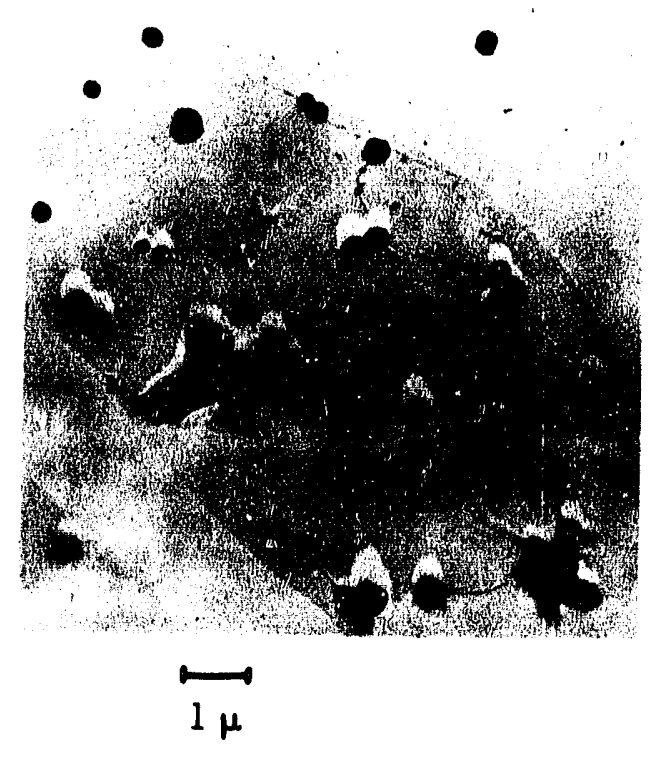

\section{FIGURE 1}

Particulate matier resulting from the passage of gaseous non-radioactive $\mathrm{RuO}_{4}$ through a laboratory $\mathrm{NaOH}$ scrubber and subsequently collected in an electrostatic precipitator. $6000 \mathrm{X}$

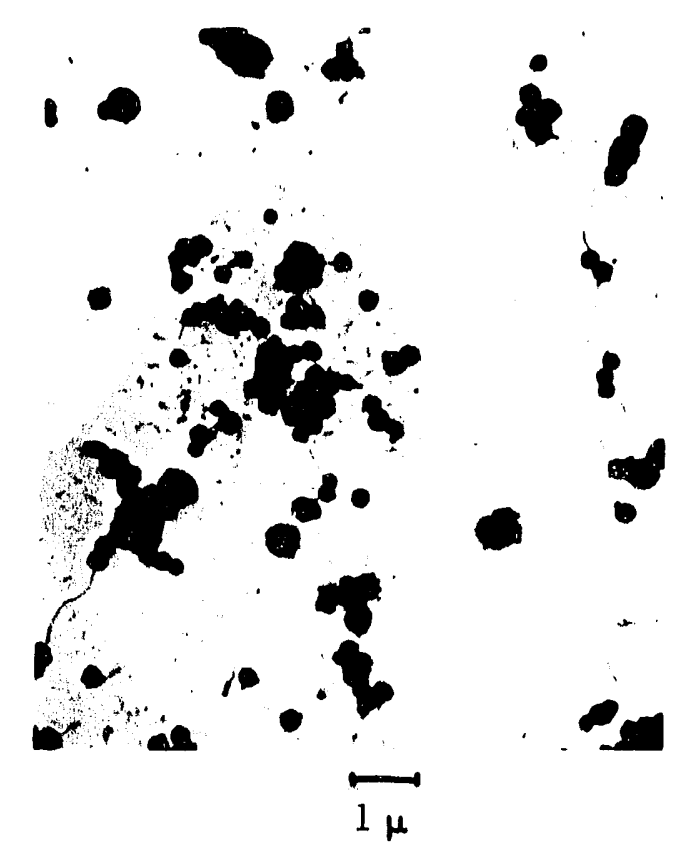

\section{FIGURE 3}

An electron photomicrograph which has been shadowed to show the spheroid character of some of the particles. This material is part of the same sample shown in Figure 2. $6500 \mathrm{X}$

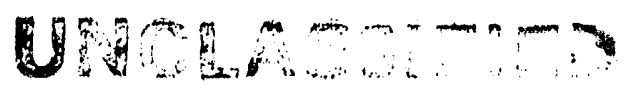




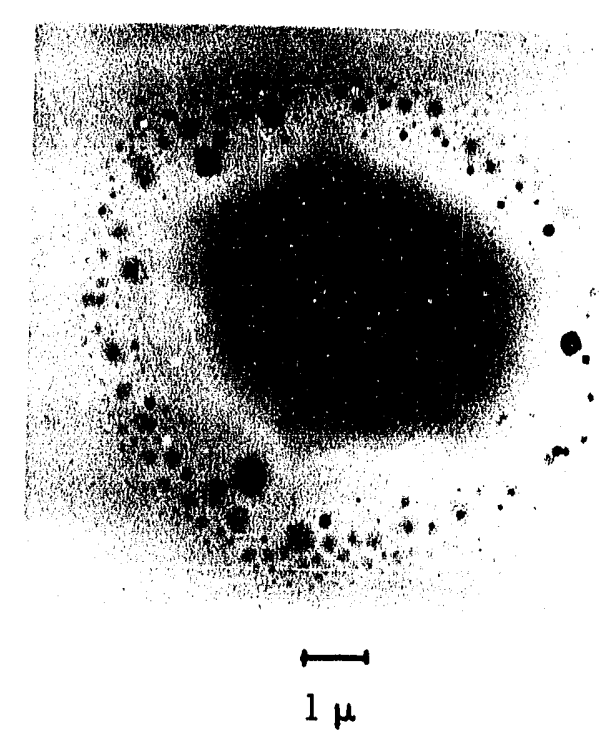

FIGURE 4

This material was collected on the 3 rd stage of a cascade impactor and is part of the same sample shown in Figure 2. $6000 \mathrm{X}$

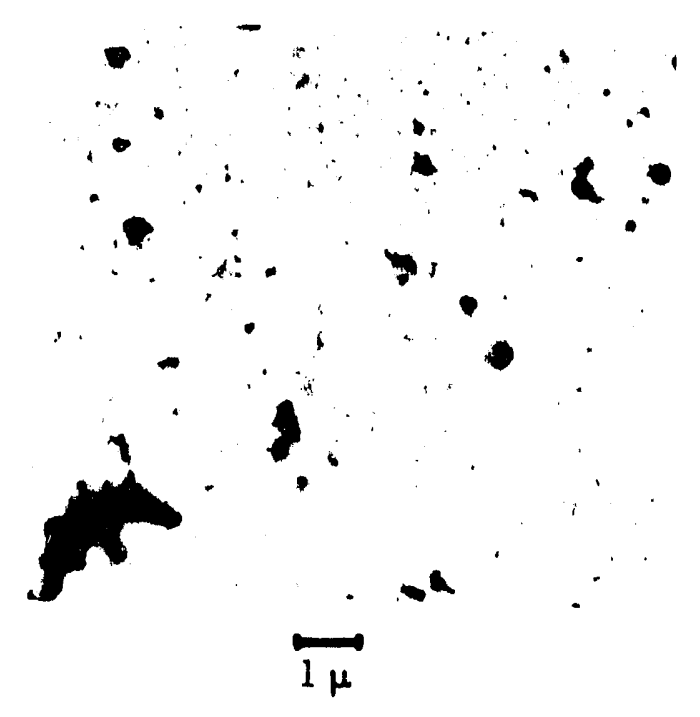

\section{FIGURE 5}

Particulate material collected in sampling head upstream from a AAA glass fiber sampling filter during air sampling in the ruthenium off-gas line downstream from the $J 1$ filter. $6000 \mathrm{X}$ 
It seems to be characteristic that gaseous $\mathrm{RuO}_{4}$ passing through a sodium hydroxide scrubber produces submicron droplets and particles. Also, that a deposit of material so small that it appears as a film even in an electron photomicrograph is associated with the deposition of these materials on the surface of sampling devices. While the droplets either contain or produce many particles that are below the electron microscope limit if resolution in size, more than $99 \%$ of all the radioactive material in the ruthenium off-gas line below the Jl filter collected in the sample shown here was on the fourth stage of the cascade impactor. It has been shown* that approximately $95 \%$ of the droplets of unit density, collected on the fourth stage of a similar cascade impactor, were in the 0.7 to 2.0 micron range.

It is also notable that AAA glass fiber sampling filters removed more than $99 \%$ of the material at this point in the off-gas line.

\section{CONCLUSION}

Silica gel had an efficiency on the order of $99.9+\%$ for the collection of both gaseous $\mathrm{RuO}_{4}$ and droplets and particles from the ruthenium off-gas Ine below the JI filter.

A silica gel bed is suggested for consideration as a collecting agent for gaseous $\mathrm{RuO}_{4}$ in the process.

The material passing through the off-gas line below the Jl filter was composed of particles and droplets which were filtered out with AAA glass fiber filters. The droplets elther contained or produced ruthenfum particles ranging in size down below the limit of resolution of the electron microscope (0.01 micron).

* Instruction Sheet No. 3018/RD, Casella and Company Lta., London. 


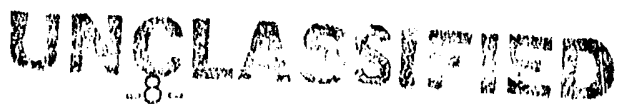

KW - 32175

A temperature of $90-95^{\circ}$ : dir it wot in itself' cause decomposition of Rue 4

when it was distilled from an aqueous solution through a clean all-glass initio
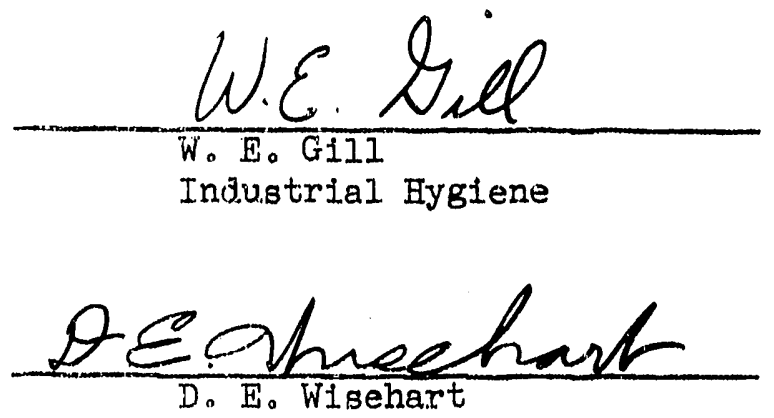

Industrial Hygiene

VEG $: R$

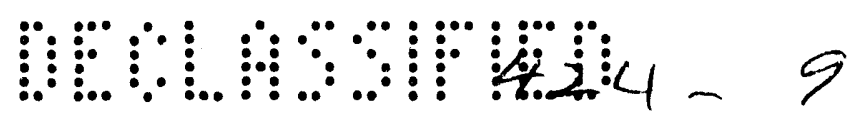



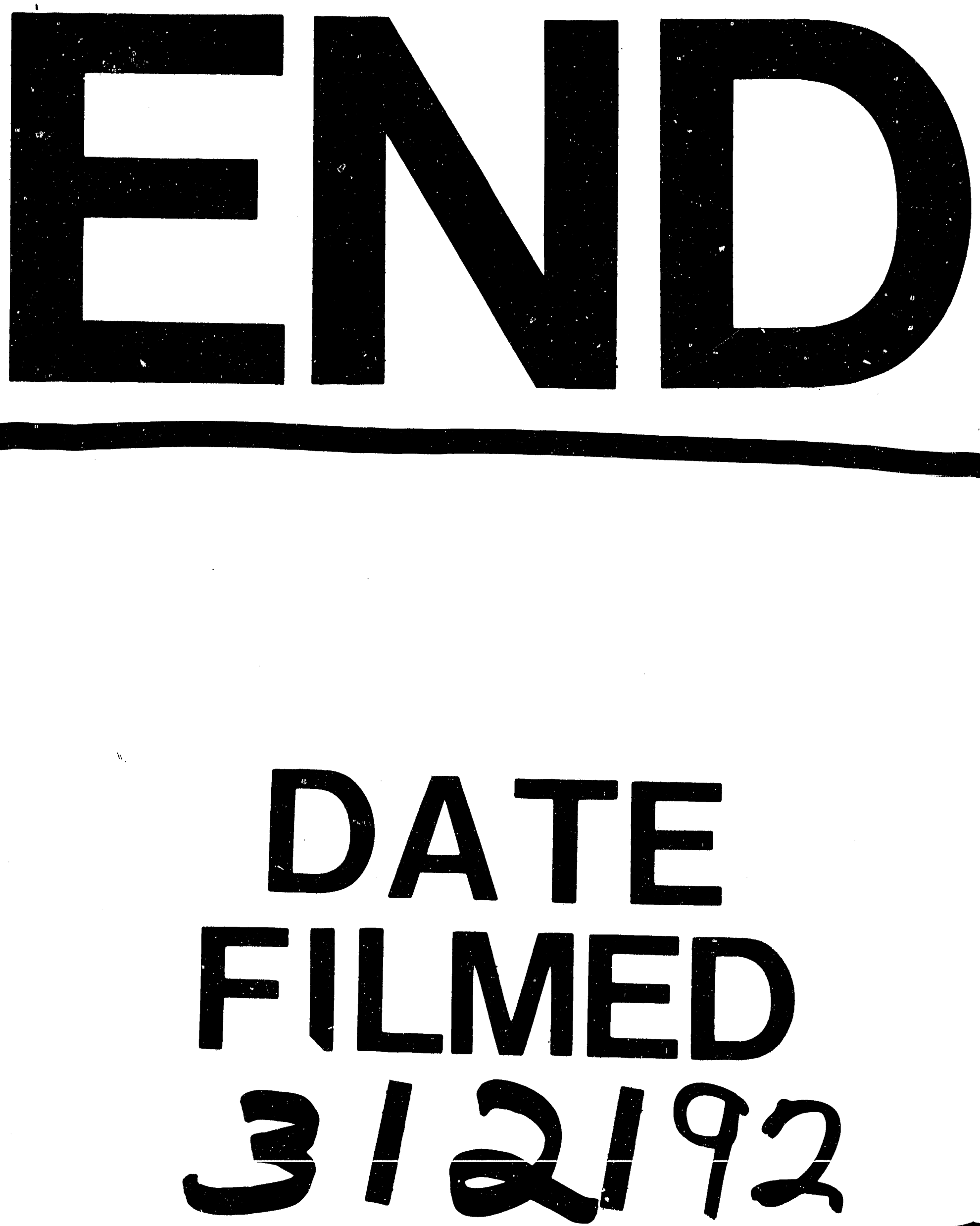

I. 
